\title{
BIOGRAPHICAL STUDIES,
}

I $534-$ I 829

Materials towards a biographical dictionary of Catholic History in the British Isles from the breach with Rome to Catholic Emancipation. 
Your recommendation of this periodical to those likely to be interested in its dissemination would be greatly appreciated. 


\section{BIOGRAPHICAL STUDIES, $1534-1829$}

Materials towards a biographical dictionary of Catholic history in the British Isles from the breach with Rome to Catholic Emancipation.

Joint Editors: A. F. Allison, of the Department of Printed Books at the British Museum, and Hon. Librarian to the Catholic Record Society.

D. Mo Rogers, of the Bodleian Library, Oxford.

$$
\begin{aligned}
& \text { Volume 1. No.4. } \\
& \text { (Part 1. Additions and Corrections) }
\end{aligned}
$$

The Arundel Press, Sussex Road, Bognor Regis. 
This publication is issued twice yearly, in January and July, to subscribers only. The annual subscription for the two parts is $8 \mathrm{~s}$. $6 \mathrm{~d}$.

Subscriptions should be addressed to:

\author{
The Manager, \\ Biographical Studies, \\ The Arundel Press, \\ Sussex Road, \\ Bognor Regis.
}

Material submitted for publication should be addressed to:

\author{
The Editor, \\ Biographical Studies, \\ c/o. the Arundel Press, \\ Sussex Road, \\ Bognor Regis.
}

